\title{
Colletotrichum gloeosporioides- Contaminated Tea Infusion Blocks Lipids Reduction and Induces Kidney Damage in Mice
}

\author{
Jin Li ${ }^{1+}$, Kang Sun ${ }^{1 \dagger}$, Qingping Ma ${ }^{1}$, Jin Chen ${ }^{2}$, Le Wang ${ }^{1}$, Dingjun Yang ${ }^{1}$, Xuan Chen ${ }^{1 \star}$ \\ and Xinghui $\mathrm{Li}^{1 *}$ \\ ${ }^{1}$ Tea Research Institute, Nanjing Agricultural University, Nanjing, China, ${ }^{2}$ Institute of Soil \& Fertilizer and Resources \& \\ Environment, Jiangxi Academy of Agricultural Science, Nanchang, China
}

OPEN ACCESS

Edited by:

Giovanna Suzzi,

Università di Teramo, Italy

Reviewed by:

Zhao Chen

University of California, Davis,

United States

Lorenzo Siroli,

Università di Bologna, Italy

*Correspondence:

Xinghui Li

Ixh@njau.edu.cn

Xuan Chen

chenxuan@njau.edu.cn

tThese authors have contributed

equally to this work.

Specialty section:

This article was submitted to

Food Microbiology,

a section of the journal

Frontiers in Microbiology

Received: 02 August 2017 Accepted: 11 October 2017

Published: 30 October 2017

Citation:

Li J, Sun K, Ma Q, Chen J, Wang L, Yang D, Chen $X$ and Li X (2017)

Colletotrichum gloeosporioides-

Contaminated Tea Infusion Blocks Lipids Reduction and Induces Kidney

Damage in Mice.

Front. Microbiol. 8:2089.

doi: 10.3389/fmicb.2017.02089
When the homogenate of fresh tea tree leaves was fermented to produce black tea beverage, the Colletotrichum gloeosporioides (main pathogen or endophyte of Camellia sinensis) may be mixed into the fermentation liquor. However, it was unclear whether C. gloeosporioides-contaminated tea beverage would damage human health. Therefore, we investigated the changes of functional components and the influences on mice. C. gloeosporioides was added to the green tea infusion. After cultivation of $48 \mathrm{~h}$, tea polyphenols, caffeine, and L-theanine decreased by 31.0, 26.2, and 8.3\%, respectively. The contaminated tea infusion showed brown stain, and produced a group of toxic materials named phthalic acid esters. The animal study showed that green tea without contamination significantly decreased levels of alanine aminotransferase, triglycerides, free fatty acids, low-density lipoprotein, and increased insulin level compared with obese mice. On the contrary, contaminated tea lost the effects on these indicators. Furthermore, the urea nitrogen and serum creatinine levels significantly increased in the contaminated tea-drinking mice. Altogether, our results indicate that C. gloeosporioides contamination can reduce the amount of functional components of green tea. Therefore, it inhibits some health-care function of lipid-lowering. In addition, the toxic components in contaminated tea infusion might induce renal damage.

Keywords: Colletotrichum gloeosporioides, food contamination, green tea, health-care function, renal damage

\section{INTRODUCTION}

Tea (Camellia sinensis) is one of the major alcohol-free beverages in the world and very popular for its health benefits, which include reduction of lipids, regulation of blood sugar levels, prevention of cardio-cerebrovascular diseases, and protection of liver (Bolling et al., 2009; Fon et al., 2011). The main functional components of tea include tea polyphenols, caffeine, and L-theanine. The leaves of

Abbreviations: ALT, alanine aminotransferase; AST, aspartate aminotransferase; BUN, blood urea nitrogen; C. gloeosporioides, Colletotrichum gloeosporioides; CAT, catalase; DBP, dibutyl phthalate; DIBP, diisobutyl phthalate; FBG, fasting blood sugar; FFA, free fatty acid; GSH, glutathione; HDL, high-density lipoprotein; HPLC, high-performance liquid chromatography; INS, insulin; ITS, internal transcribed spacer; LDL, low-density lipoprotein; LPS, lipopolysaccharide; MCP-1, monocyte chemotactic protein-1; MDA, malondialdehyde; PAEs, phthalic acid esters; S-Cr, serum creatinine; SOD, superoxide dismutase; TC, total cholesterol; TG, triglycerides; TNF- $\alpha$, tumor necrosis factor- $\alpha$.

Chemical Compounds: Caffeine (PubChem CID: 2519); L-theanine (PubChem CID: 439378); Methoxy-phenyl-Oxime (PubChem CID: 9602988); diisobutyl phthalate (PubChem CID: 6782); dibutyl phthalate (PubChem CID: 3026). 
tea tree are the raw materials for the production of tea. As a result, the quality of tea leaves could affect the contents of functional components in the tea products, thereby influencing the activities of health-care functions.

Colletotrichum gloeosporioides, is considered as the world's eighth largest plant pathogen (Dean et al., 2015) and widely distributed in mango, banana, carica papaya, strawberry, coffee, cocoa, onion, potato, and other tropical and subtropical crops. It causes anthracnose in plants which results in falling of leaves, deterioration of fruits and vegetables, as well as adverse effects on the yield and quality of agricultural products (Cannon et al., 2012). C. gloeosporioides is also one of the major pathogen of tea plants in worldwide (Copes and Thomson, 2008; Liu et al., 2015). However, C. gloeosporioides remains as parasite for a long time in tea leaves and stems as a non-pathogenic endophyte state (Rabha et al., 2016), making it difficult to distinguish the infected leaves from uninfected raw fresh tea leaves. Therefore, it is not clear whether it will impact on the quality of tea beverage products and food safety.

In this study, C. gloeosporioides fungus was added to the extracted green tea infusion and then determined the functional components of tea infusion. Subsequently, the lipid reduction effect of green tea on $\mathrm{C} 57 \mathrm{BL} / 6 \mathrm{~J}$ high-fat-fed mice was investigated, followed by verification using ICR mice. We aimed to reveal the influence of C. gloeosporioides on health-care functions and safety of tea.

\section{MATERIALS AND METHODS}

\section{C. gloeosporioides Isolation and Identification}

After surface sterilization with $75 \%$ ethanol for $2 \mathrm{~min}$ and $0.5 \%$ sodium hypochlorite for $2 \mathrm{~min}$, tea leaves were cut into $50 \mathrm{~mm} \times 50 \mathrm{~mm}$ pieces, and placed in the potato dextrose agar (PDA) medium surface. Then tea leaves were cultivated at $28^{\circ} \mathrm{C}$ for $48 \mathrm{~h}$. Pure cultures were obtained by single spore isolation and maintained on PDA plates at $28^{\circ} \mathrm{C}$ for 7 days, before observation of cultural and morphological characteristics. The cultures of C. gloeosporioides exhibited white, gray, and orange color, while the reverse side of the colonies was of white and dark gray (Figure 1A). Then, the pure hyphae were collected and the DNA extracted to measure the ITS of nuclear ribosomal DNA to identify the fungi species (Stirling, 2003). The primer sequences were ITS1: 5' -TCCGTAGGTGAACCTGCGG$3^{\prime}$ and ITS4: 5'-TCCTCCGCTTATTGATATGC-3'. Nucleotide sequences of sequenced ITS region were aligned using BLAST in $\mathrm{NCBI}^{1}$. Nucleotide sequences of ITS region of all isolates had 100\% homology with C. gloeosporioides (GenBank: KX347465.1) isolates available in the NCBI (Figure 1B).

\section{Preparation of Tea Infusion}

Fresh tea leaves were collected from Suchazao, a variety of the tea plant (C. sinensis), and then, produced into green tea after deenzyming and torrefaction. To prepare green tea infusion, $2 \mathrm{~g}$ of

\footnotetext{
${ }^{1}$ https://blast.ncbi.nlm.nih.gov/Blast.cgi
}

green tea was mixed with $100 \mathrm{~mL}$ distilled water, and extracted at $100^{\circ} \mathrm{C}$ for $30 \mathrm{~min}$. Tea infusion was collected, and sterilized at $120^{\circ} \mathrm{C}$ for $20 \mathrm{~min}$. Stored strains (PDA slants at $4^{\circ} \mathrm{C}$ ) were activated twice on PDA medium at $28^{\circ} \mathrm{C}$ for 2 days before each inoculation. Then fresh mycelium was inoculated into sterilized tea infusion. Later the green tea and mycelium-additive green tea extractions were cultured at $28^{\circ} \mathrm{C}$ for $48 \mathrm{~h}$, the changes of the color and contents of the mycelium additive extractions were no longer noticeable. So the culture conditions were selected for the follow-up test.

\section{Detection of Components in Tea Infusion}

The color of tea infusion before and after fermentation was observed by Chroma meter, CR-400 colorimeter (Osaka, Japan) (Leon et al., 2006). Color was expressed as $\mathrm{L}^{*}, \mathrm{a}^{*}$, and $\mathrm{b}^{*}$, which indicate luminosity, chromaticity on a green $(-)$ to red $(+)$ axis, and chromaticity on a blue $(-)$ to yellow $(+)$ axis, respectively (Chen et al., 2010). The volatile components in the tea infusion were detected by GC-MS method (Bruker 450GC and 320MS, Karlsruhe, Germany). Briefly, $10 \mathrm{~mL}$ extracted tea infusion and $10 \mathrm{~mL}$ contaminated tea infusion were preheated at $70^{\circ} \mathrm{C}$ for $10 \mathrm{~min}$ in $15 \mathrm{~mL}$ of headspace bottle, respectively. The solution was extracted at $50^{\circ} \mathrm{C}$ for 60 min with magnetic stirring by using Solid Phase Micro Extraction (Supelco Inc., Bellefonte, PA, United States). GC conditions were: inlet temperature $250^{\circ} \mathrm{C}$, detector temperature $250^{\circ} \mathrm{C}$, high purity helium, flow rate $1 \mathrm{~mL} / \mathrm{min}$, initial column temperature $40^{\circ} \mathrm{C}$ for $5 \mathrm{~min}$, elevated $\left(3^{\circ} \mathrm{C} / \mathrm{min}\right)$ to $210^{\circ} \mathrm{C}$ for $5 \mathrm{~min}$, then elevated $\left(10^{\circ} \mathrm{C} / \mathrm{min}\right)$ to $250^{\circ} \mathrm{C}$ for $5 \mathrm{~min}$. MS conditions were: interface temperature $280^{\circ} \mathrm{C}$, inlet temperature $250^{\circ} \mathrm{C}$, ion source temperature $230^{\circ} \mathrm{C}$, electronic energy $70 \mathrm{eV}$, quadrupole temperature $150^{\circ} \mathrm{C}$, ionization mode EI and scanning range 35-600 a.m.u. Chemical compositions were identified by searching NIST database. Moreover, spectrophotometry was used to detect the total content of polyphenols (GB/T 8313-2008), and HPLC (Alliance 2695, Waters, Milford, MA, United States) was adopted to detect the contents of caffeine (GB/T 8312-2013) and L-theanine (GB/T 23193-2008).

\section{Animals and Animal Treatments}

Healthy male C57BL/6J mice (body weight of 10-12 g, 3-4 weeks) were purchased from Laboratory Animal Centre of Yangzhou University (Permission number: 201604129), China and high-fat diet (60\% fat calories) and paired regular diet (10\% fat calories) for feeding C57BL/6J mice were purchased from TROPHIC Animal Feed High-Tech Co. Ltd., China. Healthy male ICR mice (18-20 g, 6-7 weeks) and their diet were purchased from Changzhou Cavens Laboratory Animal Co., Ltd. (Permission number: 201606808), China. The mice were housed in plastic cages in the Laboratory Animal Centre of Nanjing Agricultural University with controlled temperature $\left(20-26^{\circ} \mathrm{C}\right)$, humidity (40-70\%), light intensity $250 \mathrm{~lx}$, and 14:10 h light:dark cycle. This study was carried out in accordance with the recommendations of the guidelines of American Association for Accreditation of Laboratory Animal Care. The protocol was approved by the Animal Use and Care Committee of Nanjing Agricultural University. 

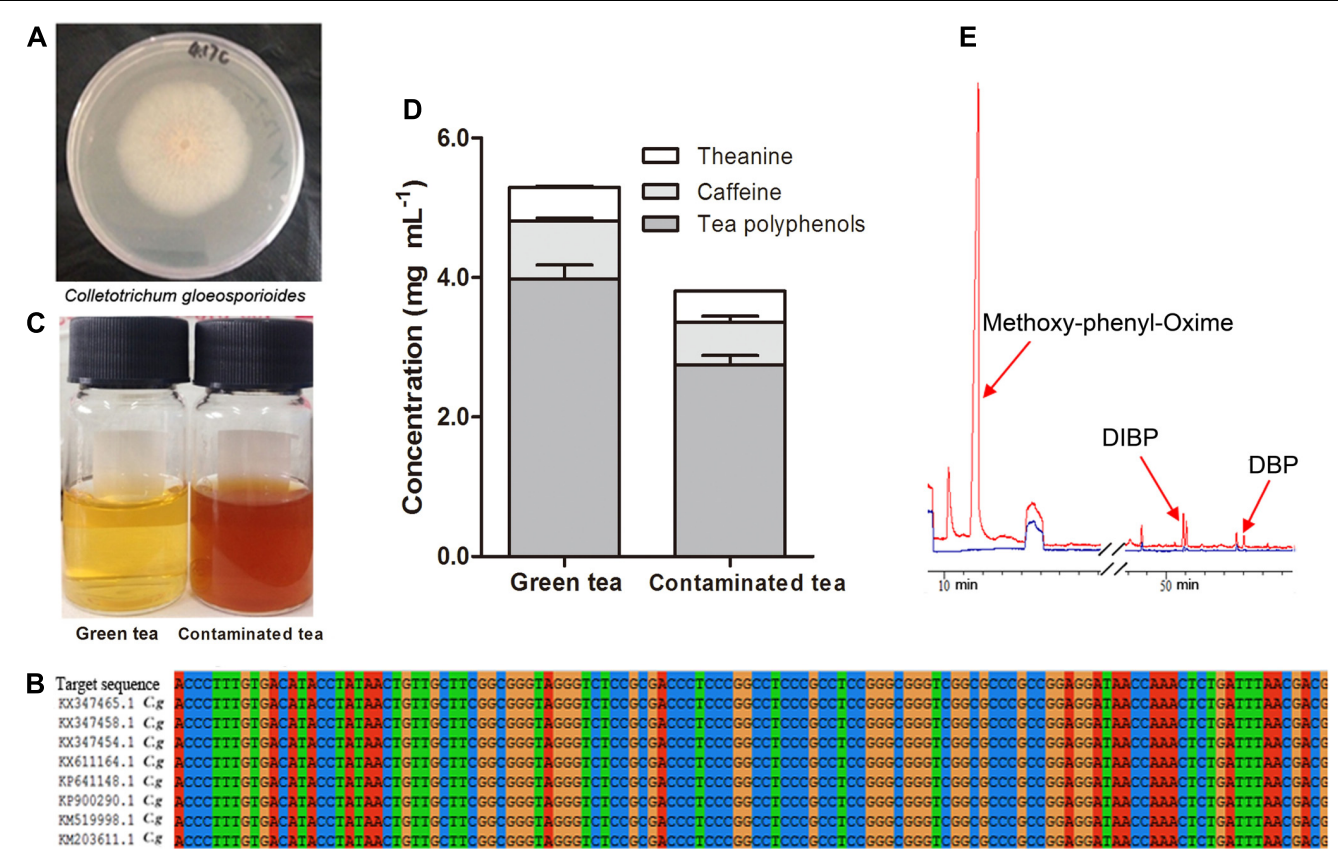

FIGURE 1 | Colletotrichum gloeosporioides and the influence on green tea infusion. The colony shape of C. gloeosporioides (A) and comparison of nucleotide sequences in ITS region on NCBI (B). Optical image of green tea and C. gloeosporioides-contaminated tea (C). Changes of functional components contents (D). GC/MS chromatograms of green tea (blue) and contaminated tea (red) (E). Mean + SEM.

Twenty-eight C57BL/6J male mice were randomized into four groups $(n=7)$. LF group were fed with low-fat diet and clear water, and HF group were fed with high-fat diet and clear water. $\mathrm{HF}+\mathrm{GT}$ group was given high-fat diet and green tea, and HF + CT group was given high-fat diet and C. gloeosporioidescontaminated tea infusion. All animals had free access to diet and drinking for 8 weeks. The amounts of drinking water and feed, as well as change of body weight were recorded daily. At the end of this experiment, mice were held without feed for $12 \mathrm{~h}$ before bleeding. In the second morning serum were collected from the tail blood for determination of fasting blood glucose (FBG).

Twenty-four normal ICR mice were randomized into three groups $(n=8)$ and fed with normal diet for 2 weeks: CK group was given clear water, GT group was given green tea, and CT group was given C. gloeosporioides-contaminated tea infusion.

\section{Tissue Preparation and Biomarker Assessments}

At the end of each experiment, mice were fasted for $12 \mathrm{~h}$, anesthetized, and sacrificed by cervical dislocation after peripheral blood collection from the ophthalmic vein. Serum was obtained by centrifugation at $10,000 \mathrm{rpm}$ for $10 \mathrm{~min}$, and stored at $-80^{\circ} \mathrm{C}$ until analysis. Liver, kidney, and small intestine tissues were excised and rinsed in ice-cold saline and then stored at $-80^{\circ} \mathrm{C}$.

For histological studies, the liver, kidney, and small intestine were obtained from treated and control C57BL/6J mice. Tissues were fixed by $4 \%$ paraformaldehyde in $0.01 \mathrm{M}$ PBS for $24 \mathrm{~h}$, and then processed for paraffin inclusion. Serial paraffin-sections
(4 mm) were stained with hematoxylin-eosin (HE) followed by light microscopy examination (KingMed Diagnostics, Nanjing, China).

Alanine aminotransferase (NJJC-C009), aspartate aminotransferase (AST) (NJJC-C010), S-Cr (NJJC-C011), and BUN (NJJC-C013) in serum were determined by spectrophotometry using commercially available kits according to the manufacturer's instructions. Serum contents of monocyte chemoattractant protein-1 (MCP-1) (RGB\&CHN-60224M), TNF- $\alpha$ (AngleGene-E21030M), LPS (AngleGene-E21618M), and INS (RGB\&CHN-60207M) were detected using ELISA Kit according to the manufacturer's instructions.

Triglyceride (TG) (NJJC-A110), TC (NJJC-A111), LDL (NJJCA113), HDL (NJC-A112), FFA (NJJC-A045), and methane dicarboxylic aldehyde (MDA) (NJJC-A003) in liver were determined by spectrophotometry using commercially available kits.

For the GSH assay, immediately after homogenization, an aliquot of homogenate was taken out to mix with trichloroacetic acid $(20 \%, w / v)$, at the volume ratio of $10: 1$. This procedure has been confirmed to be able to precipitate all proteins in the homogenate and make GSH in the homogenate stable at $4^{\circ} \mathrm{C}$ for at least $2 \mathrm{~h}$. The trichloroacetic acid-treated homogenate was centrifuged at $10,000 \mathrm{rpm}$ and $4^{\circ} \mathrm{C}$ for $5 \mathrm{~min}$. After centrifugation for $2 \mathrm{~h}$, the supernatant was mixed with dinitrobenzoic aid (20 $\mathrm{mg} \mathrm{mL}^{-1}$ in $0.2 \mathrm{M} \mathrm{PBS}, \mathrm{pH} 8.0$ ) and absorbance was read at $412 \mathrm{~nm}$ (Wang et al., 2008).

For antioxidant enzyme and other biomarkers assays, liver tissue was homogenized in ice cold $150 \mathrm{mM}$ and $\mathrm{pH} 7.2 \mathrm{PBS}$ containing $1 \mathrm{mM} \mathrm{EDTANa}_{2}(1: 9, \mathrm{w} / \mathrm{v})$, and then the homogenate 
was centrifuged at $15,000 \mathrm{rpm}$ at $4^{\circ} \mathrm{C}$ for $15 \mathrm{~min}$. Protein levels were determined by the Bradford dye-binding assay with BSA as the standard (Bradford, 1976). CAT activity was assayed on the basis of its ability to decompose $\mathrm{H}_{2} \mathrm{O}_{2}$ that was measured at $240 \mathrm{~nm}$ (Oberley et al., 1985). One unit of CAT activity was defined in terms of $1 \mathrm{nmol} \mathrm{H}_{2} \mathrm{O}_{2}$ consumed $/ \mathrm{min} / \mathrm{mg}$ protein. SOD activity was estimated by using the system of xanthine/xanthine oxidase and nitroblue tetrazolium. One unit of SOD activity was defined as the amount of protein that inhibits the rate of nitroblue tetrazolium reduction by $50 \%$ (Sun et al., 1988). Data are expressed as unit per milligram protein.

\section{Statistical Analysis}

Data were presented as the mean \pm SEM. The differences between groups were compared using ANOVA or Student's $t$-test as appropriate using GraphPad Prism (GraphPad Software, Inc., La Jolla, CA, United States). $P$-value $<0.05, P$-value $<0.01$, and $P$-value $<0.001$ were considered statistically significant.

\section{RESULTS}

\section{Effect of C. gloeosporioides Fermentation on Tea Infusion}

The green tea infusion was bright yellow, while the C. gloeosporioides-contaminated tea infusion became dark brown (Figure 1C). $L^{*}$ value was reduced from 26.53 to 18.64 , showing a decreased brightness, $a^{*}$ value was elevated from 0.66 to 4.55 , showing an increased redness, and $b^{*}$ value was reduced from 6.05 to 4.36 , showing a decreased yellowness.

After $48 \mathrm{~h}$ of fermentation, compared with green tea, the $\mathrm{pH}$ value, contents of tea polyphenols, caffeine, and L-theanine were decreased, respectively, by 12.7, 31.0, 26.2, and $8.3 \%$ in the C. gloeosporioides-contaminated tea infusion (Figure 1D). GC-MS analyses revealed that three new substances methoxy-phenyl-oxime, DIBP, and DBP were produced in C. gloeosporioides-contaminated tea compared with green tea infusion, with a retention time of $11.57,50.869$, and $54.01 \mathrm{~min}$, respectively (Figure 1E).

\section{Changes of Lipid Metabolism in C57BL/6J Mice}

After being fed for 8 weeks, body weights of C57BL/6J mice in HF group were significantly increased compared with the mice in LF group $(P<0.001)$. But $\mathrm{HF}+\mathrm{GT}$ and $\mathrm{HF}+\mathrm{CT}$ groups were significantly decreased compared with HF group $(P<0.001$, Figure 2A). There were no significantly differences between HF + GT and HF + CT groups.

Compared with HF group, drinking green tea $(\mathrm{HF}+$ GT group) can improve the obesity-induced insufficient INS $(P<0.01)$, but HF + CT group showed insignificant increase, which indicated that $C$. gloeosporioides contamination hinders the green tea's biological effect of increasing INS secretion (Figure 2B). In addition, compared with HF group, the contents of hepatic TG $(P<0.01$, Figure 2C) and FFA $(P<0.05$, Figure 2D) in $\mathrm{HF}+\mathrm{GT}$ group were significantly reduced.
However, no lower level of the above indicators was detected in $\mathrm{HF}+\mathrm{CT}$ group, suggesting that C. gloeosporioides-contaminated tea infusion hinders the lipid reduction function of green tea.

\section{Morphological and Functional Changes of Kidney, Liver, and Small Intestine in C57BL/6J Mice}

In LF group, the structure of renal glomeruli was normal, and the brush borders of renal tubular epithelium were integrity. In HF group, brush borders of renal tubular epithelium were detached, cells were swollen with a large amount of intracellular vacuoles, and part of renal tubular epithelium was detached and necrotized. In HF + GT group, the renal tubular epithelial cells were slightly swollen with a lot of intracellular vacuoles. In HF + CT group, the brush borders of the renal tubular epithelium were detached, cells were swollen with a large amount of intracellular vacuoles, and part of renal tubular epithelium were detached and necrotized, while some glomerulus were atrophic (Figure 3A). Meanwhile, compared with HF group, S-Cr value was significantly elevated in $\mathrm{HF}+\mathrm{CT}$ group $(P<0.01$, Figure 3B), suggesting that uptaking tea infusion contaminated with $C$. gloeosporioides damages the renal function in mice.

In terms of morphology, liver cells of LF group were clear and complete, structure of liver lobular was normal without steatosis. Liver cells of HF group showed mild hydropic degeneration with mild lymphocyte infiltration in the portal area. These symptoms were improved in HF + GT group, where cells were regularly and densely arranged with absence of hydroncus phenomenon. Meanwhile, cells in the HF + CT group still showed hydropic degeneration and mild lymphocytic infiltrate (Figure 3C). Then, compared with HF group, liver weight $(P<0.001$, Figure 3D) and $\operatorname{ALT}(P<0.01$, Figure $3 \mathrm{E})$ were significantly decreased in $\mathrm{HF}+\mathrm{GT}$ group, but showed no significant difference in $\mathrm{HF}$ + CT group, indicating that contaminant of C. gloeosporioides hinders the protective effect of green tea on liver cells. Meanwhile, drinking contaminated tea infusion showed no significant impact on CAT, MDA, and SOD levels related to the redox capacity of liver in C57BL/6J mice (Table 1).

HE staining was utilized to observe intestinal villus in mice. The mice in the HF group showed losing and severe short villus, as well as swollen intestinal glands. These symptoms were improved in the HF + GT and HF + CT groups (Figure 3F). LPS content prompts the health level of intestinal flora in different hosts. In this study, serum LPS content of HF + GT group decreased compared with HF group, but these two groups showed no significant changes, indicating that drinking green tea and C. gloeosporioides-contaminated tea infusion were unlikely to cause dysfunction of flora in the digestive tract of mice (Figure 3G).

\section{Changes of Inflammation Factors in C57BL/6J Mice}

Compared with HF group, the other three groups did not significantly change the contents of MCP-1 and TNF- $\alpha$ in serum (Table 1), indicating that drinking of tea infusion contaminated 

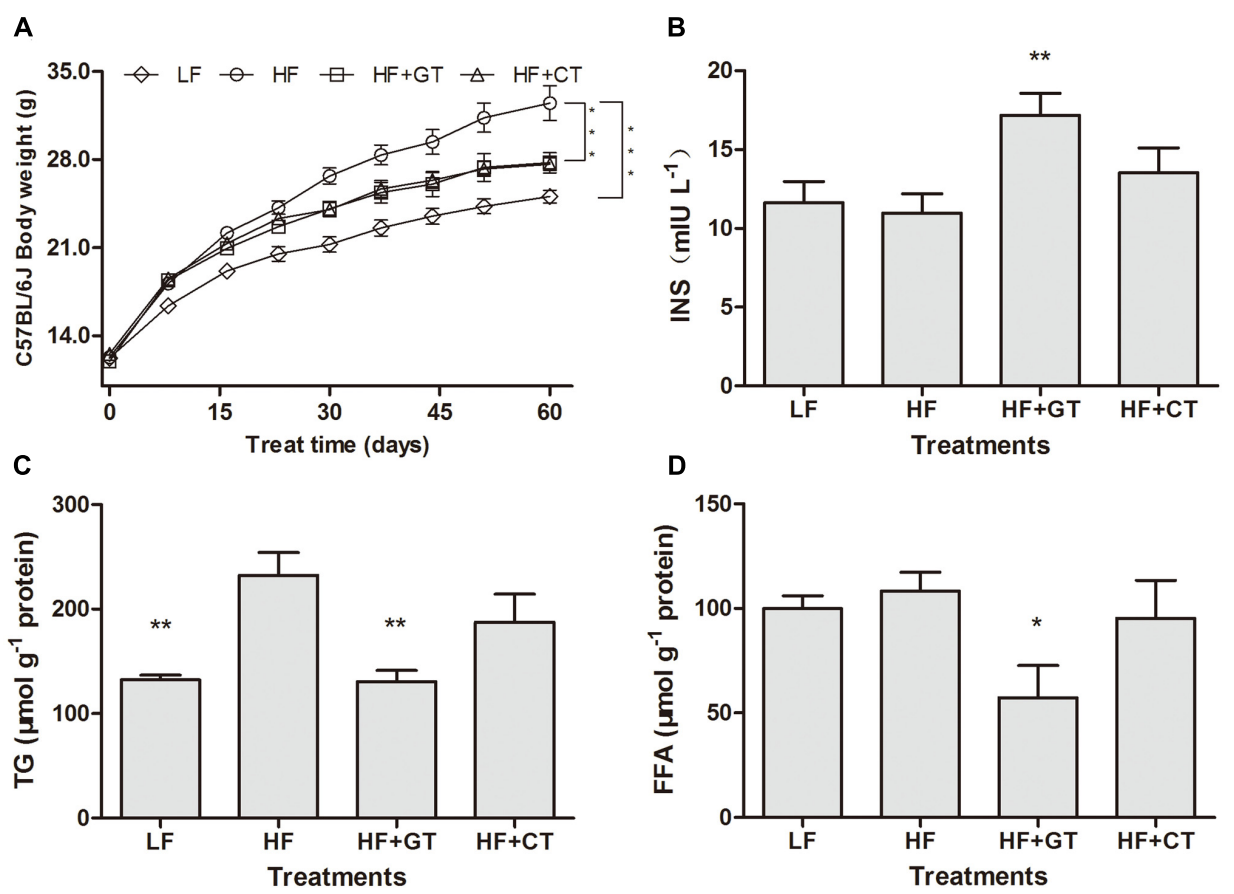

FIGURE 2 | Changes of lipid metabolism in C57BL/6J mice. Body weight of C57BL/6J mice in different groups (A). C. gloeosporioides-contaminated hindered the benefits of green tea on the increase of INS (B) and decrease of TG (C) and FFA (D). Data were compared with $\mathrm{HF}$ group. Mean \pm SEM. ${ }^{*} P<0.05$; $* *<0.01$; and $* * * P<0.001$
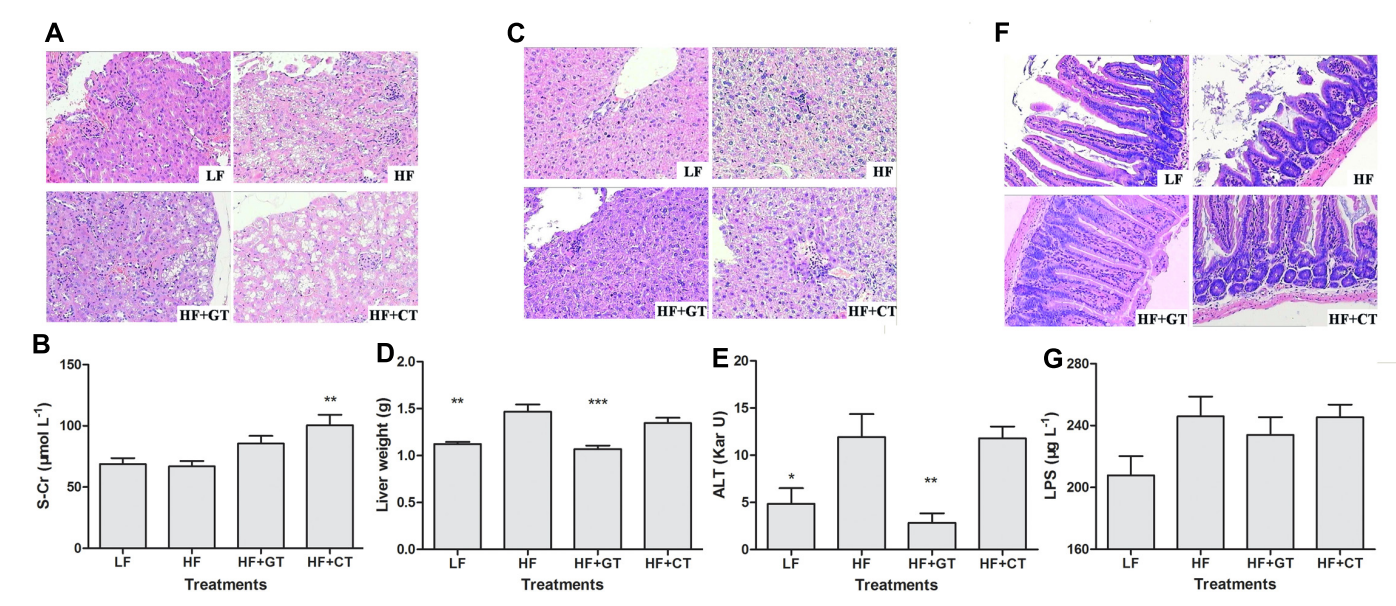

FIGURE 3 | Morphological and functional changes of kidney, liver, and small intestine in C57BL/6J mice. Kidney tissues (A), Liver (C), and small intestine (F) by HE staining. S-Cr (B), liver weight (D), ALT (E), and LPS (G) values in different groups. Data were compared with $\mathrm{HF}$ group. Mean $\pm \mathrm{SEM}$. $* P<0.05$; $* * P<0.01$; $* * * P<0.001$.

by $C$. gloeosporioides does not cause systemic inflammatory response in mice.

\section{Validation Tests with ICR Mice}

In order to rule out the possibility that the effect of C. gloeosporioides contamination only happened in C57BL/6J mice, we tried to use another commonly used model to confirm our results. After being fed for 2 weeks, the body weights of ICR mice in both GT and CT groups were reduced compared with that in the CK group. The body weight increased by $7.11 \%$ in CK group and increased by $0.71 \%$ in GT group but decreased by $8.96 \%$ in CT group (Figure 4A). At 11-14 days, there was no significant difference observed in the body weight between GT and $\mathrm{CK}$ groups, while CT group showed a significant decrease compared with CK group $(P<0.01)$. Compared with CK group, food intake in CT group was significantly decreased $(P<0.001$, Figure 4B). LDL content was significantly decreased $(P<0.05)$ in the ICR mice fed with green tea, but showed no decrease in 
TABLE 1 | Biochemical levels of C57BL/6J mice.

\begin{tabular}{|c|c|c|c|c|c|c|c|}
\hline \multirow[t]{2}{*}{ Treatments } & \multicolumn{4}{|c|}{ Liver } & \multicolumn{3}{|c|}{ Serum } \\
\hline & CAT (U mg $\left.{ }^{-1}\right)$ & MDA (mmol g $\left.\mathbf{g}^{-1}\right)$ & $\operatorname{SOD}\left(\mathrm{U} \mathrm{mg}^{-1}\right)$ & GSH (mmol $\left.\mathrm{mg}^{-1}\right)$ & MCP-1 (ng L $\left.{ }^{-1}\right)$ & TNF- $\alpha\left(p g \mathrm{~mL}^{-1}\right)$ & BUN (mmol L-1) \\
\hline LF & $0.30 \pm 0.02^{a}$ & $0.40 \pm 0.03^{a}$ & $3.14 \pm 0.29^{a}$ & $53.72 \pm 4.14^{a b}$ & $254.57 \pm 33.97^{a}$ & $243.58 \pm 23.51^{b}$ & $2.08 \pm 0.56^{a}$ \\
\hline HF & $0.19 \pm 0.01^{b}$ & $0.42 \pm 0.01^{a}$ & $2.78 \pm 0.20^{a b}$ & $47.50 \pm 2.18^{\mathrm{bc}}$ & $193.91 \pm 15.58^{a}$ & $309.08 \pm 17.32^{a}$ & $2.21 \pm 0.42^{a}$ \\
\hline $\mathrm{HF}+\mathrm{GT}$ & $0.18 \pm 0.02^{b}$ & $0.46 \pm 0.03^{a}$ & $2.80 \pm 0.31^{\mathrm{ab}}$ & $38.15 \pm 4.63^{c}$ & $294.52 \pm 42.64^{a}$ & $308.96 \pm 19.94^{a}$ & $0.44 \pm 0.06^{b}$ \\
\hline $\mathrm{HF}+\mathrm{CT}$ & $0.19 \pm 0.04^{b}$ & $0.45 \pm 0.04^{a}$ & $2.12 \pm 0.24^{b}$ & $58.97 \pm 2.97^{\mathrm{a}}$ & $237.56 \pm 40.94^{a}$ & $304.97 \pm 17.58^{a}$ & $1.22 \pm 0.32^{\mathrm{ab}}$ \\
\hline
\end{tabular}

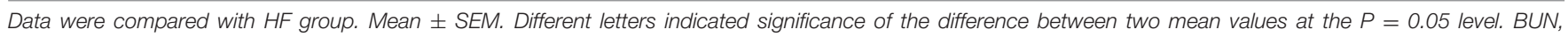

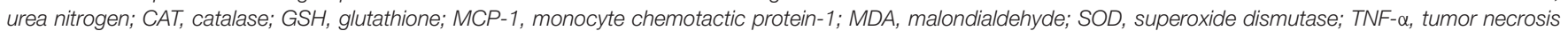
factor- $\alpha$.

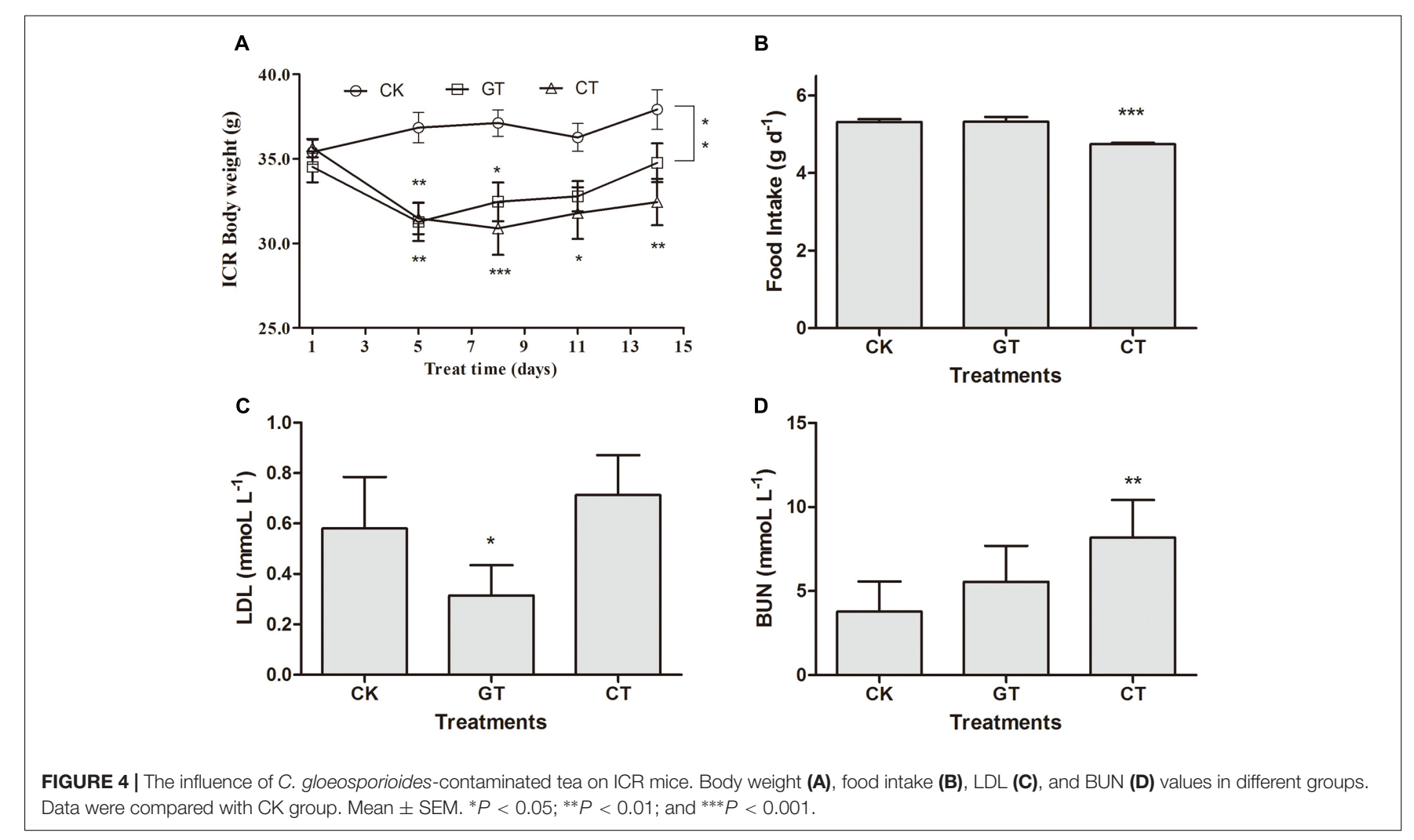

ICR mice drinking C. gloeosporioides-contaminated tea infusion, which indicated that contamination of C. gloeosporioides hinders the original lipid reduction function of green tea (Figure 4C). Compared with the $\mathrm{CK}$ group, BUN value in $\mathrm{CT}$ group was significantly elevated $(P<0.01)$, while no significant increase was observed in mice of the GT group, suggesting that tea infusion contaminated with C. gloeosporioides damaged the renal function in ICR mice (Figure 4D). In addition, there were no differences between groups in TG, TC, HDL, ALT, AST, and S-Cr assays (Table 2).

\section{DISCUSSION}

The three major functional components of tea are tea polyphenols, caffeine, and L-theanine. A larger number of studies have confirmed that tea polyphenols has significant antioxidant
TABLE 2 | Biochemical levels of ICR mice.

\begin{tabular}{lccr}
\hline Treatments & CK & GT & CT \\
\hline TG $\left(\mathrm{mmol} \mathrm{L}^{-1}\right)$ & $2.01 \pm 0.16^{\mathrm{ab}}$ & $1.87 \pm 0.14^{\mathrm{b}}$ & $2.47 \pm 0.24^{\mathrm{a}}$ \\
$\mathrm{TC}\left(\mathrm{mmol} \mathrm{L}^{-1}\right)$ & $7.40 \pm 0.66^{\mathrm{a}}$ & $6.88 \pm 0.31^{\mathrm{a}}$ & $7.10 \pm 0.48^{\mathrm{a}}$ \\
HDL $\left(\mathrm{mmol} \mathrm{L}^{-1}\right)$ & $2.60 \pm 0.15^{\mathrm{a}}$ & $2.77 \pm 0.16^{\mathrm{a}}$ & $2.93 \pm 0.12^{\mathrm{a}}$ \\
ALT $(\operatorname{Kar} \mathrm{U})$ & $10.45 \pm 3.93^{\mathrm{a}}$ & $12.02 \pm 3.87^{\mathrm{a}}$ & $13.13 \pm 3.98^{\mathrm{a}}$ \\
AST $($ Kar U) & $24.46 \pm 5.13^{\mathrm{a}}$ & $27.81 \pm 8.35^{\mathrm{a}}$ & $25.28 \pm 6.72^{\mathrm{a}}$ \\
S-Cr $\left(\mu \mathrm{mol} \mathrm{L}{ }^{-1}\right)$ & $355.1 \pm 11.29^{\mathrm{ab}}$ & $323.4 \pm 8.939^{\mathrm{b}}$ & $383.4 \pm 15.03^{\mathrm{a}}$
\end{tabular}

Data were compared with CK group. Mean \pm SEM. Different letters indicated significance of the difference between two mean values at the $P=0.05$ level. ALT, alanine aminotransferase; AST, aspartate aminotransferase; HDL, high-density lipoprotein; S-Cr, serum creatinine; TC, total cholesterol; TG, triglycerides.

effects (Forester and Lambert, 2011), and also exhibits functions in prevention and treatment of cancer and kidney diseases (Hisamura et al., 2006). Other functions included are anti- 
hypertensive, anti-inflammatory, hypolipidemic, strengthens INS activity (Anderson and Polansky, 2002). Caffeine, also known as 1,3,7-trimethylxanthine mainly acts as central nervous system stimulant (Nehlig et al., 1992). And it is demonstrated that the combination of catechins and caffeine induced inhibition of fat accumulation in mice through the improvement of hepatic lipid metabolism (Sugiura et al., 2012). L-Theanine, known as $N$-ethyl$\gamma$-L-glutamine is a kind of unique free amino acid in tea leaves and has positive effects on allaying excitement (Kimura et al., 2007), and protecting the liver (Jiang et al., 2012). It is considered that green tea has beneficial effects against obesity, and the polyphenols or catechin in green tea demonstrates highest biological activity. In this study, three functional components (tea polyphenols, L-theanine, and caffeine) were significantly decreased when extracted green tea infusion was contaminated by C. gloeosporioides. Therefore, the functions of lipid-lowering, increasing INS secretion, and protecting liver greatly attenuated.

In this study, three new volatile components methoxyphenyl-oxime, DIBP, and DBP were detected in tea infusion contaminated with C. gloeosporioides using GC-MS method. Methoxy-phenyl-oxime is a microbial fermentation product, which can be found in cheese (Jung et al., 2013) and haw juice (Zhao et al., 2015). DIBP and DBP have similar chemical properties, and belong to PAEs, which are colorless transparent liquids with slightly aromatic odor. PAEs are broad class fatsoluble compounds, commonly used as plasticizers, and are also detected in a variety of natural plant volatile oil ( $\mathrm{Li}$ et al., 2008; Wang et al., 2009). They are widespread in human living environment, and can enter human body through breathing, diet, drinking water, and skin contact. They have been identified as fourth class of toxic chemicals, which can cause endocrinal and reproductive toxicity in humans (Kamrin, 2009; MartinoAndrade and Chahoud, 2010), and developmental toxicity in experimental animals (Fisher, 2004). In addition, epidemiological studies have shown that high exposure to phthalates can damage children's intelligence and behavioral capacity (Cho et al., 2010), and also can cause asthma and allergic symptoms (Bornehag et al., 2004). In this study, DIBP or DBP was not detected in green tea. We speculated that they were present in the form of complexes with other components of tea infusion. However, whether the renal damage is related to PAEs, requires further investigation.

Endophytes are co-evolution products of microorganisms and plants, which are found in almost all the plants (Santoyo et al., 2016). On the one hand, some endophytes play active roles in plant growth and human usage (Tejesvi and Pirttilä, 2010; Waqas et al., 2013). On the other hand, some endophytes play negative roles (Kulkarni et al., 2007; Faeth et al., 2010), by producing toxic secondary metabolites and thus displaying serious impact on human food safety (Peraica et al., 1999; Ranaldi et al., 2009). In this study, the contaminated tea infusion had an adverse effect on mice, including that blocking green tea-induced

\section{REFERENCES}

Anderson, R. A., and Polansky, M. M. (2002). Tea enhances insulin activity. J. Agric. Food Chem. 50, 7182-7186. doi: 10.1021/jf020514c decreasing levels of ALT, TG, FFA, LDL, and increased INS level compared with obese mice and increasing the BUN and S-Cr levels which was indicated that it induced kidney damage. Therefore, C. gloeosporioides control in tea plant cultivation should be reinforced. Picking of infected leaves should be avoided especially to produce tea concentrate and extractive such as caffeine and tea polyphenols with fresh leaves as raw materials. Enough attention should be paid to establishing convenient, rapid and economical methods to test fresh tea leaves.

\section{CONCLUSION}

Contamination with tea plant C. gloeosporioides pathogenic fungi caused brown stain in the green tea infusion, and produced toxic compound such as DIBP and DBP. And three main functional components of tea (tea polyphenols, caffeine and Ltheanine) were lowered, respectively. The animal experiments revealed that C. gloeosporioides-contamination tended to damage the renal function (elevated S-Cr and BUN) in mice, and to hinder the original functions of green tea, such as protecting liver (lowered ALT), regulating lipid metabolism (decreased LDL and FFA) as well as modulating glucose metabolism (increased INS). Increased attention should be paid to the safety of tea processing in order to establish specific rules of supervisory control.

\section{ETHICS STATEMENT}

This study was carried out in accordance with the recommendations of the guidelines of American Association for Accreditation of Laboratory Animal Care. The protocol was approved by the Animal Use and Care Committee of Nanjing Agricultural University.

\section{AUTHOR CONTRIBUTIONS}

JL and KS finished major experiments and wrote the main manuscript text. JL, KS, QM, and LW prepared Figures 1-4. JC revised the manuscript. XC and XL designed all experiments and revised the manuscript. All authors reviewed the manuscript.

\section{FUNDING}

This work was supported by the earmarked fund for Modern Agro-industry Technology Research System of China (CARS-23), the Priority Academic Program Development of Jiangsu Higher Education Institutions, the National Natural Science Foundation of Jiangsu Province (BK20160735), and the Postdoctoral Science Foundation of Jiangsu Province (1601078C).

Bolling, B. W., Chen, C. Y., and Blumberg, J. B. (2009). Tea and health: preventive and therapeutic usefulness in the elderly? Curr. Opin. Clin. Nutr. Metab. Care 12, 42-48. doi: 10.1097/MCO.0b013e32831b $9 \mathrm{c} 48$ 
Bornehag, C. G., Sundell, J., Weschler, C. J., Sigsgaard, T., Lundgren, B., Hasselgren, M., et al. (2004). The association between asthma and allergic symptoms in children and phthalates in house dust: a nested case-control study. Environ. Health Perspect. 112, 1393-1397. doi: 10.1289/ehp.7187

Bradford, M. M. (1976). A rapid and sensitive method for the quantitation of microgram quantities of protein utilizing the principle of protein-dye binding. Anal. Biochem. 72, 248-254. doi: 10.1016/0003-2697(76)90527-3

Cannon, P. F., Damm, U., Johnston, P. R., and Weir, B. S. (2012). Colletotrichum - current status and future directions. Stud. Mycol. 73, 181-213. doi: 10.3114/ $\operatorname{sim} 0014$

Chen, Z., Zhu, C., Zhang, Y., Niu, D., and Du, J. (2010). Effects of aqueous chlorine dioxide treatment on enzymatic browning and shelf-life of fresh-cut asparagus lettuce (Lactuca sativa L.). Postharvest Biol. Technol. 58, 232-238. doi: 10.1016/j.postharvbio.2010.06.004

Cho, S. C., Bhang, S. Y., Hong, Y. C., Shin, M. S., Kim, B. N., Kim, J. W., et al. (2010). Relationship between environmental phthalate exposure and the intelligence of school-age children. Environ. Health Perspect. 118, 1027-1032. doi: 10.1289/ehp.0901376

Copes, W. E., and Thomson, J. L. (2008). Survival analysis to determine the length of the incubation period of camellia twig blight caused by Colletotrichum gloeosporioides. Plant Dis. 92, 1177-1182. doi: 10.1094/PDIS-92-8-1177

Dean, R., Van Kan, J. A. L., Pretorius, Z. A., Pietro, A. D., Spanu, P. D., Rudd, J. J., et al. (2015). The Top 10 fungal pathogens in molecular plant pathology. Mol. Plant Pathol. 16, 414-430.

Faeth, S. H., Hayes, C. J., and Gardner, D. R. (2010). Asexual endophytes in a native grass: tradeoffs in mortality, growth, reproduction, and alkaloid production. Microb. Ecol. 60, 496-504. doi: 10.1007/s00248-010-9643-4

Fisher, J. S. (2004). Environmental anti-androgens and male reproductive health: focus on phthalates and testicular dysgenesis syndrome. Reproduction 127, 305-315. doi: 10.1530/rep.1.00025

Fon, S. M., Yang, W. S., Gao, S., Gao, J., and Xiang, Y. B. (2011). Epidemiological studies of the association between tea drinking and primary liver cancer: a meta-analysis. Eur. J. Cancer Prev. 20, 157-165. doi: 10.1097/CEJ.0b013e328344 7497

Forester, S. C., and Lambert, J. D. (2011). The role of antioxidant versus prooxidant effects of green tea polyphenols in cancer prevention. Mol. Nutr. Food Res. 55, 844-854. doi: 10.1002/mnfr.201000641

Hisamura, F., Kojimayuasa, A., Kennedy, D. O., and Matsuiyuasa, I. (2006). Protective effect of green tea extract and tea polyphenols against FK506induced cytotoxicity in renal cells. Basic Clin. Pharmacol. Toxicol. 98, 192-196. doi: 10.1111/j.1742-7843.2006.pto_284.x

Jiang, W., Gao, M., Sun, S., Bi, A., Xin, Y., Han, X., et al. (2012). Protective effect of L-theanine on carbon tetrachloride-induced acute liver injury in mice. Biochem. Biophys. Res. Commun. 422, 344-350. doi: 10.1016/j.bbrc.2012.05.022

Jung, H., Ganesan, P., Lee, S., and Kwak, H. (2013). Comparative study of flavor in cholesterol-removed Gouda cheese and Gouda cheese during ripening. J. Dairy Sci. 96, 1972-1983. doi: 10.3168/jds.2012-5644

Kamrin, M. A. (2009). Phthalate risks, phthalate regulation, and public health: a review. J. Toxicol. Environ. Health B Crit. Rev. 12, 157-174. doi: 10.1080/ 10937400902729226

Kimura, K., Ozeki, M., Juneja, L. R., and Ohira, H. (2007). L-Theanine reduces psychological and physiological stress responses. Biol. Psychol. 74, 39-45. doi: 10.1016/j.biopsycho.2006.06.006

Kulkarni, A. A., Kelkar, S. M., Watve, M. G., and Krishnamurthy, K. V. (2007). Characterization and control of endophytic bacterial contaminants in in vitro cultures of Piper spp., Taxus baccata subsp. wallichiana, and Withania somnifera. Can. J. Microbiol. 53, 63-74. doi: 10.1139/w06-106

Leon, K., Pedreschi, M. F., and Leon, J. (2006). Color measurement in L ${ }^{*} \mathrm{a} \sim{ }^{*} \mathrm{~b} \sim *$ units from RGB digital images. Food Res. Int. 39, 1084-1091. doi: 10.1016/j. foodres.2006.03.006

Li, X.-L., Luan, K., Hu, J.-J., Li, X.-F., and Xiang, S. (2008). Aroma volatile compound analysis of SPME headspace and extract samples from crabapple
(Malus sp.) fruit using GC-MS. Agric. Sci. China 7, 1451-1457. doi: 10.1016/ S1671-2927(08)60402-2

Liu, F., Weir, B. S., Damm, U., Crous, P. W., Wang, Y., Liu, B., et al. (2015). Unravelling Colletotrichum species associated with Camellia: employing ApMat and GS loci to resolve species in the C. gloeosporioides complex. Persoonia 35, 63-86. doi: 10.3767/003158515X687597

Martino-Andrade, A. J., and Chahoud, I. (2010). Reproductive toxicity of phthalate esters. Mol. Nutr. Food Res. 54, 148-157. doi: 10.1111/j.1742-7843.2007.00180.x

Nehlig, A., Daval, J. L., and Debry, G. (1992). Caffeine and the central nervous system: mechanisms of action, biochemical, metabolic and psychostimulant effects. Brain Res. Rev. 17, 139-170. doi: 10.1016/0165-0173(92)90012-B

Oberley, L., Spitz, D., and Greenwald, R. (1985). CRC Handbook of Methods for Oxygen Radical Research. Boca Raton, FL: CRC Press.

Peraica, M., Radić, B., Lucić, A., and Pavlović, M. (1999). Toxic effects of mycotoxins in humans. Bull. World Health Organ. 77, 754-766.

Rabha, A. J., Naglot, A., Sharma, G. D., Gogoi, H. K., Gupta, V. K., Shreemali, D. D., et al. (2016). Morphological and molecular diversity of endophytic Colletotrichum gloeosporioides from tea plant, Camellia sinensis (L.) O. Kuntze of Assam, India. Genet. Eng. Biotechnol. J. 14, 181-187. doi: 10.1016/j.jgeb.2015. 12.003

Ranaldi, G., Caprini, V., Sambuy, Y., Perozzi, G., and Murgia, C. (2009). Intracellular zinc stores protect the intestinal epithelium from Ochratoxin A toxicity. Toxicol. In Vitro 23, 1516-1521. doi: 10.1016/j.tiv.2009.08.012

Santoyo, G., Morenohagelsieb, G., Del, C. O. M., and Glick, B. R. (2016). Plant growth-promoting bacterial endophytes. Microbiol. Res. 183, 92-99. doi: 10.1016/j.micres.2015.11.008

Stirling, D. (2003). DNA extraction from fungi, yeast, and bacteria. Methods Mol. Biol. 226, 53-54.

Sugiura, C., Nishimatsu, S., Moriyama, T., Ozasa, S., Kawada, T., and Sayama, K. (2012). Catechins and caffeine inhibit fat accumulation in mice through the improvement of hepatic lipid metabolism. J. Obes. 2012:520510. doi: 10.1155/ 2012/520510

Sun, Y., Oberley, L. W., and Li, Y. (1988). A simple method for clinical assay of superoxide dismutase. Clin. Chem. 34, 497-500.

Tejesvi, M. V., and Pirttilä, A. M. (2010). "Potential of tree endophytes as sources for new drug compounds," in Endophytes of Forest Trees. Forestry Sciences, Vol. 80, eds A. Pirttilä and A. Frank (Dordrecht: Springer).

Wang, R., Wang, R., and Yang, B. (2009). Extraction of essential oils from five cinnamon leaves and identification of their volatile compound compositions. Innov. Food Sci. Emerg. Technol. 10, 289-292. doi: 10.1016/j.ifset.2008.12.002

Wang, X., Zhang, J., and Xu, T. (2008). Thioredoxin reductase inactivation as a pivotal mechanism of ifosfamide in cancer therapy. Eur. J. Pharmacol. 579, 66-73. doi: 10.1016/j.ejphar.2007.10.012

Waqas, M., Khan, A. L., and Lee, I. J. (2013). Bioactive chemical constituents produced by endophytes and effects on rice plant growth. J. Plant Interact. 9, 478-487. doi: 10.1080/17429145.2013.860562

Zhao, Y., Wang, Y., Wang, J., Wu, Z., Sun, Z., Tian, T., et al. (2015). "Characterization of volatile constituents of Chinese hawthorn (Crataegus spp.) Fruit Juices," in Advances in Applied Biotechnology, eds T.-C. Zhang and M. Nakajima (Berlin: Springer), 533-545.

Conflict of Interest Statement: The authors declare that the research was conducted in the absence of any commercial or financial relationships that could be construed as a potential conflict of interest.

Copyright (c) 2017 Li, Sun, Ma, Chen, Wang, Yang, Chen and Li. This is an openaccess article distributed under the terms of the Creative Commons Attribution License (CC BY). The use, distribution or reproduction in other forums is permitted, provided the original author(s) or licensor are credited and that the original publication in this journal is cited, in accordance with accepted academic practice. No use, distribution or reproduction is permitted which does not comply with these terms. 